\title{
A Brief History of a Research Project
}

By

Sune Åkerman

University of Uppsala

For the social sciences and the humanities in the Nordic countries the 1960 s were characterized by a number of large projects. New resources administrated by research councils and other contributors were made available. At the same time increased demands were placed on systematic data collection and data processing within many university subjects. When the flow of post-graduate students rapidly increased it also became clear that an improved planning of the research projects was necessary. The need for new forms of organization also rapidly became felt within the sphere of postgraduate tuition. Consequently, many of the large research projects in the Nordic countries were planned more in the form of training projects which came to work almost as independent institutions. In contrast to the research institutes of this kind found in many other countries, very few of the Nordic projects are permanent. They have worked on a time-limited budget with the aim of producing a final report within a period generally no longer than three to six years.

This special volume of American Studies in Scandinavia can be said to constitute one of these final reports. The idea of Nordic cooperation on the subject of mass emigration to North America was originally brought up at an international conference on "Nordic Emigration" at Uppsala in 1969. At that time prominent emigration researchers such as Ingrid Semmingsen in Oslo and Kristian Hvidt in Copenhagen had long been active in the field of mass emigration in their own countries. Research groups had also been formed in Turku and Uppsala. With the reserve of knowledge thus available at the start of the Nordic project, it was natural that the main research effort was directed at comparative studies and, in addition, at conducting more penetrating studies in certain spheres of particular interest, especially those treated grudgingly by earlier researchers. 
The organizational set-up of the joint research work leaves its mark on the present report. An initial survey of Nordic mass emigration by Ingrid Semmingsen is followed by a fairly comprehensive article by the Norwegian archivist and historian Andres A. Svalestuen, who links together the micro-investigations on the parish level made in Iceland, Denmark, Norway, Sweden and Finland. These local studies, directed at selected problems, make up the largest part of the project's work and were conducted during 1971-1975. The very limited economic resources available have naturally not permitted a more systematic selection of parishes throughout the Nordic countries. A more satisfactory strategy would have been to select type-areas which would have represented the geographical variety found in the countries concerned. An investigation along these lines was originally attempted for the Swedish part of the project but it was found to require excessively large inputs of financial resources and staff. Under such circumstances there is a very large risk that the scattered local investigations would not give representative results. However, this has been counteracted by the comprehensive research conducted at several Nordic universities that has yielded about a hundred micro-studies of the type conducted at Torslev, Ullensaker, Vopnafjordur, Toholampi, Alfta and Julita. Here it should also be mentioned that the microstudies were conducted within the frame of the analysis of aggregated statistics that has long been the traditional working method within emigration research and one that we wanted to develop further. The careful mapping of the emigration from the five Nordic countries has been an important part of the project and has also helped us to place the results in a wider temporal and geographical relationship. (The Nordic Emigration Atlas will be published in a separate volume in 1978.)

If the whole mass emigration is regarded as a single process, certain phases can be distinguished: an initial phase, when only a few scattered individuals accept a new migratory behaviour; a growth phase, where an increasing number of people are drawn into a stream of migrants to a given destination; a saturation phase, which signifies the culmination of the migratory behaviour, and a regression phase marking the decreasing need of and interest in a certain migratory alternative.

Research in the Nordic countries has paid particular attention to such migratory phases as well as to mass emigration as an innovation process. We have also been interested in the aspects of mass emigra- 
tion that suggest the presence of self-generating effects. These themes are taken up by the Icelandic historian Helgi Skúli Kjartansson who has treated the initial phase in the emigration from Iceland, by the Uppsala historians Bo Kronborg, Thomas Nilsson and Sune Akerman, and by Finland's Ieading emigration expert, Reino Kero. In these analyses it was found valuable to consider the entire population movements within and between European countries. This is clearly illustrated in the contribution by the Danish historian Arne Vagndrup.

Another approach, one extremely neglected internationally - at least in historical studies - concerns how individuals and groups of individuals arrive at their decision to migrate. Here, once again, a process approach can be useful. Problems concerning a population's potential inclination to migrate, the maturation of their decision to move, the selective mechanisms that can be distinguished, the conditions that finally release the decision to migrate, and the fascinating glimpses of a psychological or sociological nature, have been the subject of detailed theoretical consideration and empirical studies. Examples of this research are given in this volume by the Umeå historian Kjell Soderberg in his methodologically innovative study of the selectivity of migration as well as in the contribution by by Kronborg, Nilsson and Åkerman.

It would be misleading to conceal the extreme difficulties encountered in this Nordic team-work. The large geographic distances between the research groups has complicated coordination and and problems of staff etc. have sometimes caused the project to waver somewhat. This has not been entirely concealed in the final editing of this volume. However, it would be unjust not to mention the value the project may have had as a forum for contacts, as illustrated by the series of seminars and conferences arranged by the project for several years, and the large number of students and researchers that have taken part, directly or indirectly, in the research work. An early result of this team-work was the publication of "Emigrationen fra Norden indtil 1. Verdenskrig. Rapporter til det Nordiske Mistorikermsde i Ksbenhavn 1971, 9-12 August", with contributions from all the Nordic countries. 